\title{
Power Quality Improvement in Grid Connected Wind Energy System Using Facts Device and PID Controller
}

\author{
D. Srinivas ${ }^{1}$, M. Rama Sekhara Reddy ${ }^{2}$ \\ ${ }^{\prime}$ (M.Tech (EPS), Department of EEE, JNTUACE, Pulivendula, A.P, India, ) \\ ${ }^{2}$ (Assistant Professor, Department of EEE, JNTUACE, Pulivendula, A.P, India,)
}

\begin{abstract}
The wind energy generation, utilization and its grid penetration in electrical grid are increasing worldwide. The wind generated power is always fluctuating due to its time varying nature and causing stability problems. This weak interconnection of wind generating source in the electrical network affects the power quality and reliability. The influence of the wind turbine in the grid system concerning the power quality measurements are the active power, reactive power, variation of voltage, flicker, harmonics, and electrical behavior of switching operation and these are measured according to national international guidelines. The STATCOM provides reactive power support to wind generator and load. The Battery Energy Storage System (BESS) is generally required to compensate the fluctuation generated by wind turbine. The paper study demonstrates the power quality problem due to installation of wind turbine with the grid. The proposed control scheme to mitigate the power quality issues for power quality improvement in the grid connected wind energy generation is simulated using MATLAB/ SIMULINK in power system block set. The control scheme has a capability to cancel out the harmonic parts of the load current and maintains the source voltage and current in-phase. The proposed control scheme supports the reactive power demand for the wind generator and load at point of common coupling (PCC) in the grid system, thus it gives an opportunity to enhance the utilization factor of transmission line.
\end{abstract}

Keywords: - BESS, Harmonics, Induction generator, Power quality, PID controller, STATCOM, THD.

\section{Introduction}

In recent years, wind energy has become one of the most important and promising sources of renewable energy, which demands additional transmission capacity and better means of maintaining system reliability. To have sustainable growth and social progress, it is necessary to meet the energy need by utilizing the renewable energy resources like wind. The need to integrate the renewable energy like wind energy into power system is to make it possible to minimize the environmental impacts. Wind energy conversion systems are the fastest growing renewable source of electrical energy having tremendous environmental, social, and economic benefits [1].

Power Quality is defined as power that enables the equipment to work properly. A power quality problem can be defined as any deviation of magnitude, frequency, or purity from the ideal sinusoidal voltage waveform. Good power quality [2] is benefit to the operation of electrical equipment, but poor power quality will produce great harm to the power system. However, the generated power from wind energy conversion system is always fluctuating due to the fluctuation nature of the wind. Therefore injection of the wind power into an electric grid affects the power quality. The important factors to be considered in power quality measurement are the active power, reactive power, variation of voltage, flicker, harmonics, and electrical behavior of switching operation [3].

In this proposed scheme Static Synchronous Compensator (STATCOM) is connected at a point of common coupling with a battery energy storage system (BESS) to mitigate the power quality issues. Therefore STATCOM [4] provides Reactive Power support to wind generator and load. The battery energy storage is integrated to sustain the real power source under fluctuating wind power. The STATCOM control scheme for the grid connected wind energy generation system for power quality improvement is simulated using MATLAB/SIMULINK in power system block set.

In this paper there will be the analysis of factors which are responsible for the power quality problems in the wind energy conversion system and implementation of proper control scheme for power quality improvement in the wind energy conversion system connected to the grid. The paper is organized as follows. The section II introduces the power quality standards, issues and its consequences of wind turbine. The section III introduces the grid coordination rule for grid quality limits. The section IV describes the topology for power quality improvement. The section V describes the control scheme. The section VI and VII describes the control system performance and conclusion respectively. 


\section{Power quality improvement}

Power Quality Issues and Its Consequences:-

Power quality problem is any power problem manifested in voltage, current, or frequency deviation that results in failure or malfunctioning of customer equipment.

Power quality can be simply defined as shown in the interaction diagram:

-Voltage Sags

- Voltage Swells

-Blackouts/Brownouts

-Transients, Glitches

$\bullet$ Inrush

- Overcurrent

- Flickering
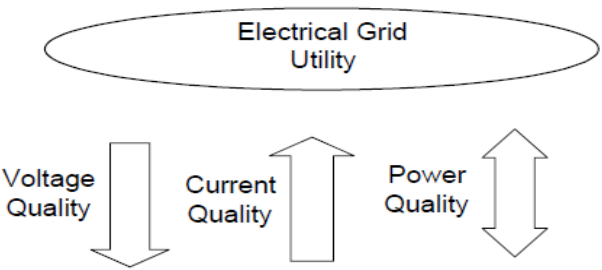

Nonlinear Loads Consumers

\author{
-Harmonics \\ -Waveform Distortion \\ -Arc Type \\ -Temporal \\ - Converter Type \\ -Saturation Type \\ -NLL-Analog/Digital \\ Switching
}

Power quality is a two-pronged issue, with electronic equipment playing both villain and victim. Most new electronic equipment, while more efficient than its mechanical predecessors, consumes electricity differently than traditional mechanical appliances.

Power supply quality issues [5] and resulting problems are consequences of the increasing use of solid state switching devices, nonlinear and power electronically switched loads, electronic type loads the advent and wide spread of high power semiconductor switches at utilization, distribution and transmission leaves have non sinusoidal currents.

\section{Causes and consequences:}

The causes and consequences of power quality problems can be traced to a specific type of electrical disturbance. In most of industry, more than $90 \%$ of the electric motor with inverter driven application.Poor power quality causes trouble in receptacle/transmission equipment and electronic equipment malfunctions / Failure. Power quality is a common problem for both electric power suppliers and users. it is not easy to identify whether the cause of poor power supply quality is at the supplier's system or the user's system

Power disturbances can be classified into the following categories.
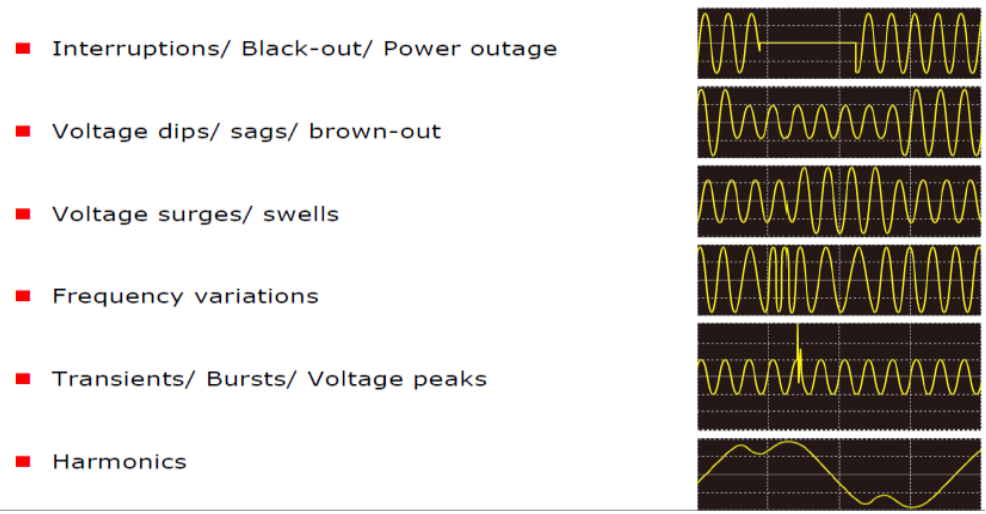

\section{$>$ Power outages:}

Power outages are total interruptions of electrical supply. Utilities have installed protection equipment that briefly interrupts power to allow time for a disturbance to dissipate.

- Causes: Ice storms; lightning; wind; utility equipment failure.

- Effects: Complete disruption of operation.

$>$ Voltage fluctuations:

Voltage fluctuations are changes or swings in the steady-state voltage above or below the designated input range for a piece of equipment. Fluctuations include both sags and swells.

- Causes: Large equipment start-up or shut down; sudden change in load.

- Effects: Data errors; memory loss; equipment shutdown; flickering lights; motors stalling/stopping. 


\section{$>$ Transients:}

Transients, commonly called "surges," are sub-cycle disturbances of very short duration that vary greatly in magnitude. When transient occur, thousands of voltage can be generated into the electrical system, causing problems for equipment down the line.

- Causes: Lighting; equipment start-up and shutdown; welding equipment.

- Effects: Processing errors; computer lock-up; burned circuit boards; degradation of electrical insulation; equipment damage.

$>$ Harmonics:

Harmonics are the periodic steady-state distortions of the sine wave due to equipments generating frequency other than the standard 60 cycles per second.

- Causes: Electronic ballasts; non-linear loads; variable frequency drives.

- Effects: Overheating of electrical equipment; random breakers tripping; hot neutrals.

\section{Grid Co-Ordination Rule}

The first grid code was focused on the distribution level, after the blackout in the United State in August 2003. The United State wind energy industry took a stand in developing its own grid code for contributing to a stable grid operation. The rules for realization of grid operation of wind generating system at the distribution network are defined as-per IEC-61400-21. The grid quality characteristics and limits are given for references that the customer and the utility grid may expect. According to energy economic law, the operator of transmission grid is responsible for the organization and operation of interconnected system.

\section{A. Voltage Rise (u):}

The voltage rise at the point of common coupling can be approximated as a function of maximum apparent power Smax of the turbine, the grid impedances $\mathrm{R}$ and $\mathrm{X}$ at the point of common coupling and the phase angle $\emptyset$ given in Eq.1

$$
\begin{aligned}
& \Delta \mathrm{u}=\mathrm{S}_{\max }(\mathrm{R} \cos \emptyset-\mathrm{X} \sin \emptyset) / \mathrm{U}^{2} \\
& \text { Where, } \\
& \Delta \mathrm{u}-\text { voltage rise } \\
& \mathrm{S}_{\max }-\text { maximum apparent power } \\
& \emptyset-\text { phase difference. } \\
& \mathrm{U} \text { - nominal voltage of grid } \\
& \text { The limiting voltage rise value is }<2 \% .
\end{aligned}
$$

\section{B. Voltage Dips (d):}

The voltage dips is due to startup of wind turbine and it causes a sudden reduction of voltage. It is the relative \% voltage change due to switching operation of wind turbine. The decrease of nominal voltage change is given in Eq. 2.

Where,

$$
\mathrm{d}=\mathrm{K}_{\mathrm{u}} \mathrm{S}_{\mathrm{n}} / \mathrm{S}_{\mathrm{k}}
$$

$\mathrm{d}$ is relative voltage change.

$\mathrm{S}_{\mathrm{n}}$ is rated apparent power.

$\mathrm{S}_{\mathrm{k}}$ is short circuit apparent power.

$\mathrm{K}_{\mathrm{u}}$ is sudden voltage reduction factor.

C. Flicker:

The acceptance voltage dips limiting value is $\leq 3 \%$.

The measurements are made [6] for maximum number of specified switching operation of wind turbine with 10-min period and 2-h period are specified, as given in Eq. 3

Where,

$$
\mathrm{P}_{\mathrm{lt}}=\mathrm{C}\left(\psi_{\mathrm{k}}\right) \mathrm{S}_{\mathrm{n}} / \mathrm{S}_{\mathrm{k}}
$$

$\mathrm{P}_{\mathrm{lt}}=$ long term flicker.

$\mathrm{C}\left(\psi_{\mathrm{k}}\right)=$ flicker coefficient calculated from Rayleigh distribution of the wind speed

The Limiting Value for flicker coefficient is about $\leq 0.4$, for average time of $2 \mathrm{~h}$.

\section{Harmonics:}

The harmonic distortion is assessed for variable speed turbine with an electronic power converter at the point of common connection. The total harmonic voltage distortion of voltage is given as in Eq. 4 .

$$
V_{T H D}=\sqrt{\sum_{h=2}^{40} \frac{V_{n}^{2}}{V_{1}}} 100
$$


Where,

$\mathrm{V}_{\mathrm{n}}$ is the nth harmonic voltage.

$\mathrm{V}_{1}$ is the fundamental frequency $(50) \mathrm{Hz}$.

The THD limit for $132 \mathrm{KV}$ is $3 \%$.

THD of current ITHD is given as in Eq. 5.

$$
I_{T H D}=\sqrt{\sum_{h=2}^{40} \frac{I_{n}}{I_{1}}} 100
$$

Where,

$\mathrm{I}_{\mathrm{n}}$ is the nth harmonic current.

$\mathrm{I}_{1}$ is the fundamental frequency $(50) \mathrm{Hz}$.

The THD of current and limit for $132 \mathrm{KV}$ is $<2.5 \%$.

\section{E. Grid Frequency:}

The grid frequency in India is specified in the range of $47.5-51.5 \mathrm{~Hz}$, for wind farm connection. The wind farm [7] shall able to withstand change in frequency up to $0.5 \mathrm{~Hz} / \mathrm{s}$.

\section{Topology for power quality improvement}

The STATCOM [8] based current control voltage source inverter injects the current into the grid in such a way that the source current are harmonic free and their phase-angle with respect to source voltage has a desired value. The injected current will cancel out the reactive part and harmonic part of the load and induction generator current, thus it improves the power factor and the power quality.

To accomplish these goals, the grid voltages are sensed and are synchronized in generating the current command for the inverter. The proposed grid connected system is implemented for power quality improvement at point of common coupling as shown in Fig. 1.

The grid connected system in Fig. 1, consists of wind energy generation system and battery energy storage system with STATCOM.

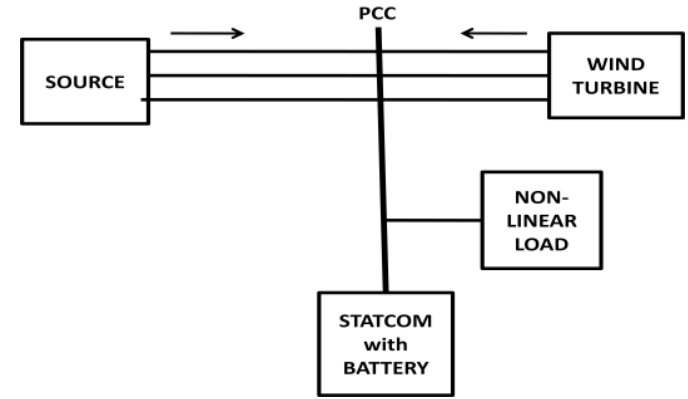

Fig.1. Line diagram of Grid connected system for power quality improvement.

\section{Wind Energy Generating System:}

The induction generator is used in the proposed scheme because of its simplicity, it does not require a separate field circuit, it can accept constant and variable loads, and has natural protection against short circuit. The available power of wind energy system is presented as under in Eq.6.

$$
\mathrm{P}_{\text {wind }}=\frac{1}{2} \rho A V^{3}{ }_{\text {wind }}
$$

Where,

$\rho(\mathrm{kg} / \mathrm{m})$ is the air density.

$\mathrm{A}(\mathrm{m})$ is the area swept out by turbine blade.

$\mathrm{V}_{\text {wind }}$ is the wind speed in meters.

It is not possible to extract all kinetic energy of wind, thus it extract a fraction of power in wind, called power coefficient $C p$ of the wind turbine, and is given in Eq.7.

$$
\mathrm{P}_{\text {mech }}=\mathrm{C}_{\mathrm{p}} \mathrm{P}_{\text {wind }}
$$

Where $C p$ is the power coefficient, depends on type and operating condition of wind turbine. This coefficient can be express as a function of tip speed ratio $\lambda$ and pitch angle $\theta$. The mechanical power produce by wind turbine is given in Eq. 8 .

$$
\mathrm{P}_{\text {mech }}=\frac{1}{2} \rho \Pi \mathrm{R}^{2} \mathrm{~V}^{3}{ }_{\text {wind }} \mathrm{C}_{\mathrm{p}}
$$




\section{STATCOM - Static Synchronous Compensator:}

The STATCOM (or SSC) is a shunt-connected reactive power compensation device that is capable of generating and/ or absorbing reactive power and in which the output can be varied to control the specific parameters of an electric power system. It is in general a solid-state switching converter capable of generating or absorbing independently controllable real and reactive power at its output terminals when it is fed from an energy source or energy-storage device at its input terminals. Specifically, the STATCOM considered in this chapter is a voltage-source converter that, from a given input of dc voltage, produces a set of 3-phase ac-output voltages, each in phase with and coupled to the corresponding ac system voltage through a relatively small reactance (which is provided by either an interface reactor or the leakage inductance of a coupling transformer). The dc voltage is provided by an energy-storage capacitor.

A STATCOM can improve power-system performance in such areas as the following:

a. The power-oscillation damping in power transmission systems.

b. The dynamic voltage control in transmission and distribution systems.

c. The transient stability.

d. The voltage flicker control.

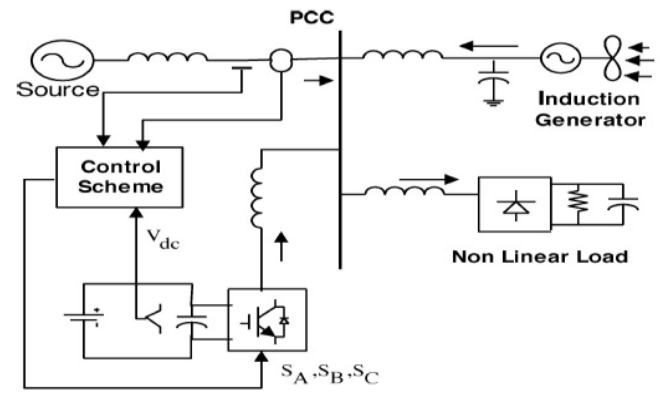

\section{System Operation}

Fig.2. System operational scheme in grid system

The shunt connected STATCOM with battery energy storage [9] is connected with the interface of the induction generator and non-linear load at the PCC in the grid system. The STATCOM compensator output is varied according to the controlled strategy, so as to maintain the power quality norms in the grid system. The current control strategy is included in the control scheme that defines the functional operation of the STATCOM compensator in the power system. A single STATCOM using insulated gate bipolar transistor is proposed to have a reactive power support, to the induction generator and to the nonlinear load in the grid system. The main block diagram of the system operational scheme is shown in Fig. 2.

\section{Control Scheme}

The control scheme approach is based on injecting the currents into the grid using "PID controller." Using such technique, the controller keeps the control system variable between boundaries of hysteresis area and gives correct switching signals for STATCOM operation.

The control system scheme for generating the switching signals to the STATCOM is shown in Fig. 3.

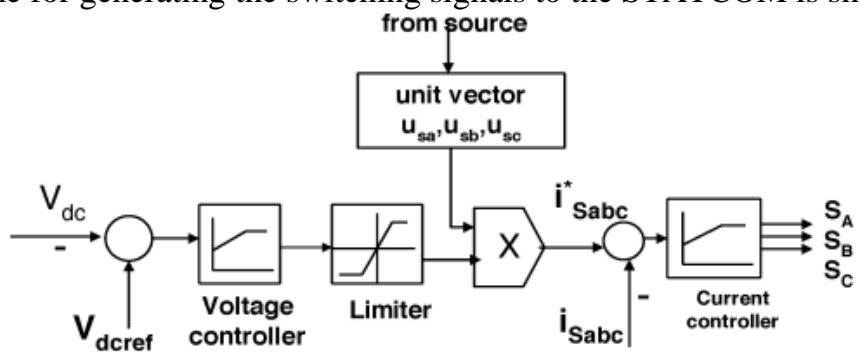

Fig.3 control scheme

\section{System Performance}

The proposed control scheme is simulated using SIMULINK in power system block set. The system parameter for given system is given Table I. The system performance of proposed system under dynamic condition is also presented. 
A. Voltage Source Current Control-Inverter Operation:

The three phase injected current into the grid from STATCOM will cancel out the distortion caused by the nonlinear load and wind generator. The IGBT based three-phase inverter is connected to grid through the transformer. The generation of switching signals from reference current is simulated within hysteresis band of 0.08 . The choice of narrow hysteresis band switching in the system improves the current quality and control signal of switching frequency within its operating band.

TABLE - I

SYSTEM PARAMETERS

\begin{tabular}{|l|l|l|}
\hline S.no & Parameters & Ratings \\
\hline 1 & Grid Voltage & 3-phase,415V,50Hz \\
\hline 2 & Induction & $\begin{array}{l}3.35 \mathrm{KVA}, 415 \mathrm{~V}, 50 \mathrm{~Hz}, \mathrm{P}=4 \text {, Speed } \\
=1440 \mathrm{rpm}, \mathrm{R}_{\mathrm{s}}=0.01 \Omega \\
\mathrm{R}_{\mathrm{r}}=0.015 \Omega, \mathrm{L}_{\mathrm{s}}=0.06 \mathrm{H}, \mathrm{L}_{\mathrm{r}}=0.06 \mathrm{H}\end{array}$ \\
\hline 3 & Line series Inductance & $0.05 \mathrm{mH}$ \\
\hline 4 & Inverter Parameters & $\begin{array}{l}\text { DC Link Voltage }=800 \mathrm{~V} \\
\text { DC Link Capacitance }=100 \mu \mathrm{F} \\
\text { Switching Frequency }=2 \mathrm{kHz}\end{array}$ \\
\hline 5 & IGBT Rating & $\begin{array}{l}\text { Collector Voltage }=1200 \mathrm{~V}, \text { Forward } \\
\text { Current }=50 \text { A, } \\
\text { Gate voltage }=20 \mathrm{~V}, \\
\text { Power dissipation }=310 \mathrm{~W}\end{array}$ \\
\hline 6 & Load Parameter & Non-Linear Load $25 \mathrm{KW}$ \\
\hline
\end{tabular}

\section{B. STATCOM-Performance under Load Variations:}

The wind energy generating system is connected with grid [11] having the nonlinear load. The performance of the system is measured by switching the STATCOM at time $t=0.7 \mathrm{~s}$ in the system and how the STATCOM responds to the step change command for increase in additional load at $1.0 \mathrm{~s}$ is shown in the simulation.

When STATCOM controller is made ON, without change in any other load condition parameters, it starts to mitigate for reactive demand as well as harmonic current. This additional demand is fulfill by STATCOM compensator [12]. The simulation diagram of proposed control scheme with STATCOM is shown in Fig. 4.

The output of STATCOM is shown in Fig.5. The DC link voltage regulates the source current in the grid system, so the DC link voltage is maintained constant across the capacitor. The source current waveform in simulated model is analyzed with STATCOM and without STATCOM operation.

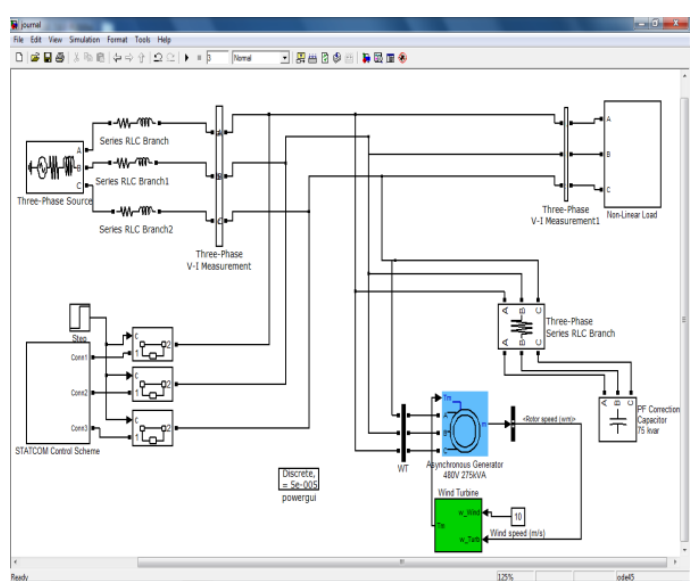

Fig.4 proposed control scheme with STATCOM

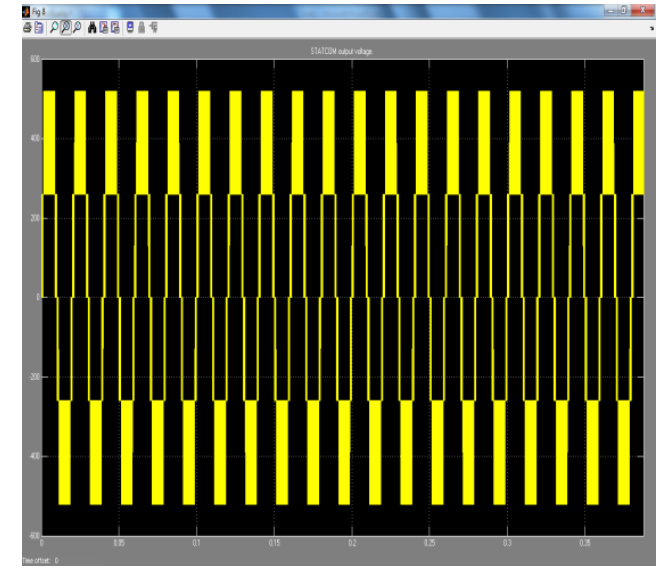

Fig.5 STATCOM OUTPUT Voltage

The above tests with proposed scheme has not only power quality improvement [13] feature but it also has sustain capability to support the load with the energy storage through the batteries [14]. The DC link voltage and Current through capacitor are shown in Fig.6.The source voltage and source current at PCC is shown in Fig.7. 


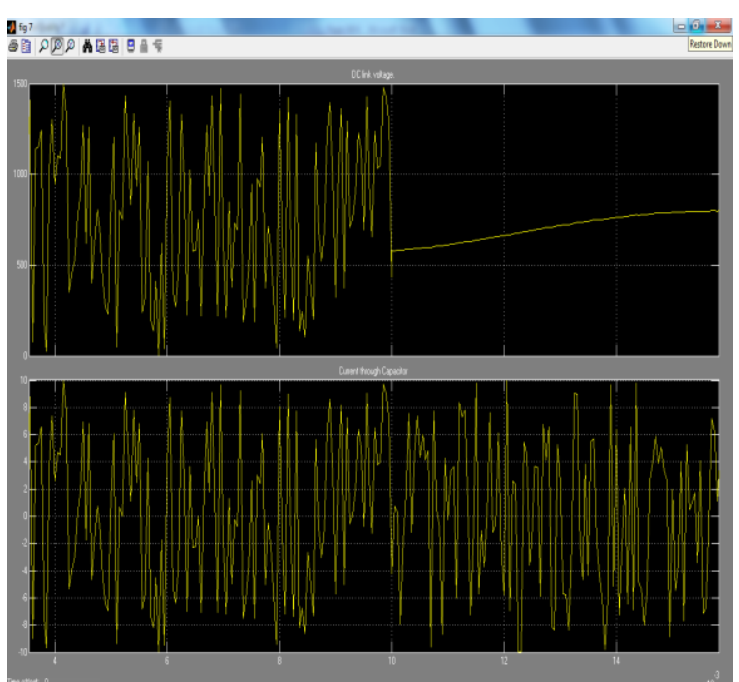

Fig.6. DC link voltage and Current through capacitor

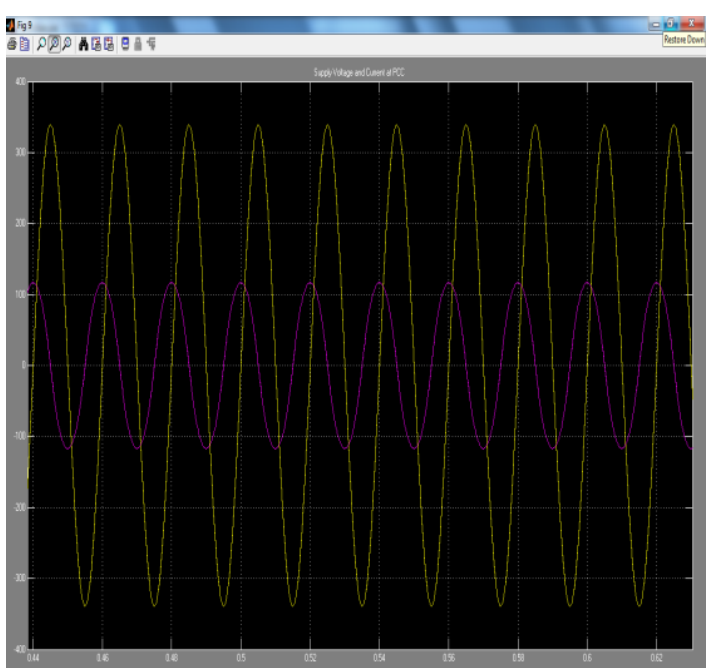

Fig.7. Source voltage and Source current at PCC

The outputs of source current, load current, inverter injected current and wind generator current are shown in Fig.8.The switching signal within a control hysteresis band is shown in Fig.9
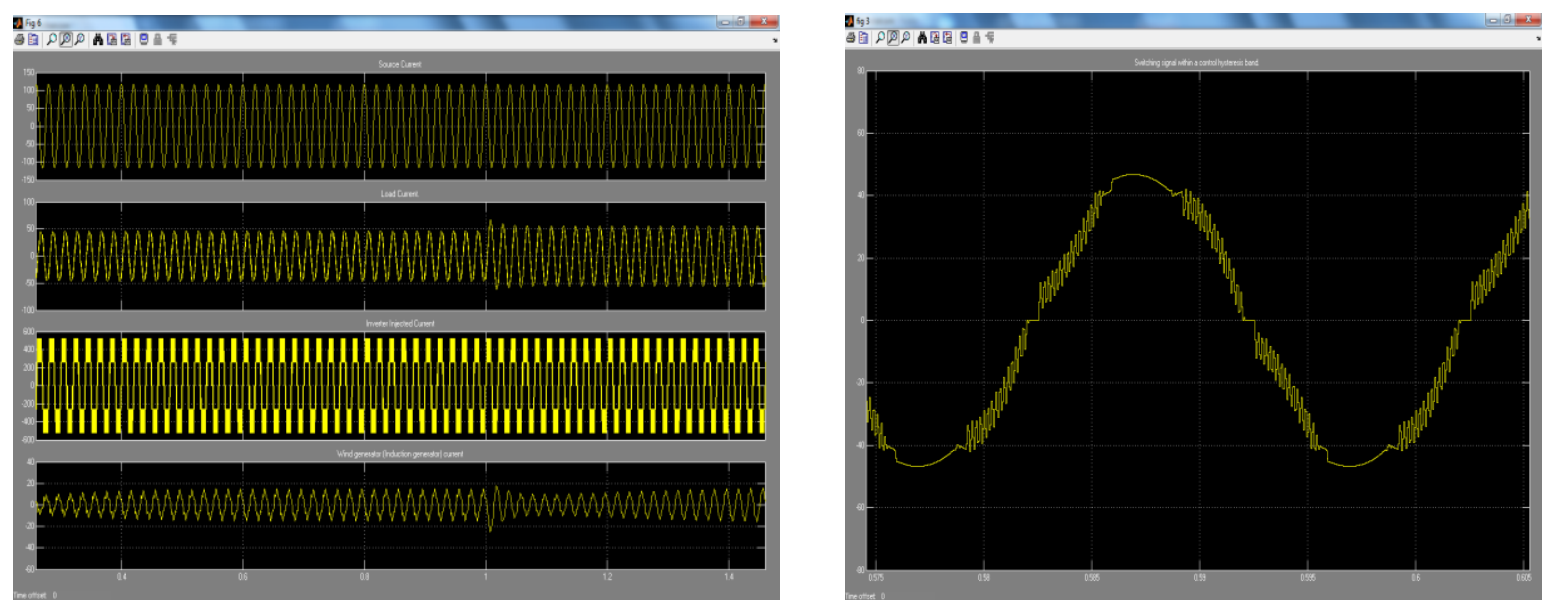

Fig.8. (a) source current, (b) load current, (c) Inverter injected current and (d) wind generator current. Fig.9.The switching signal within a control hysteresis band

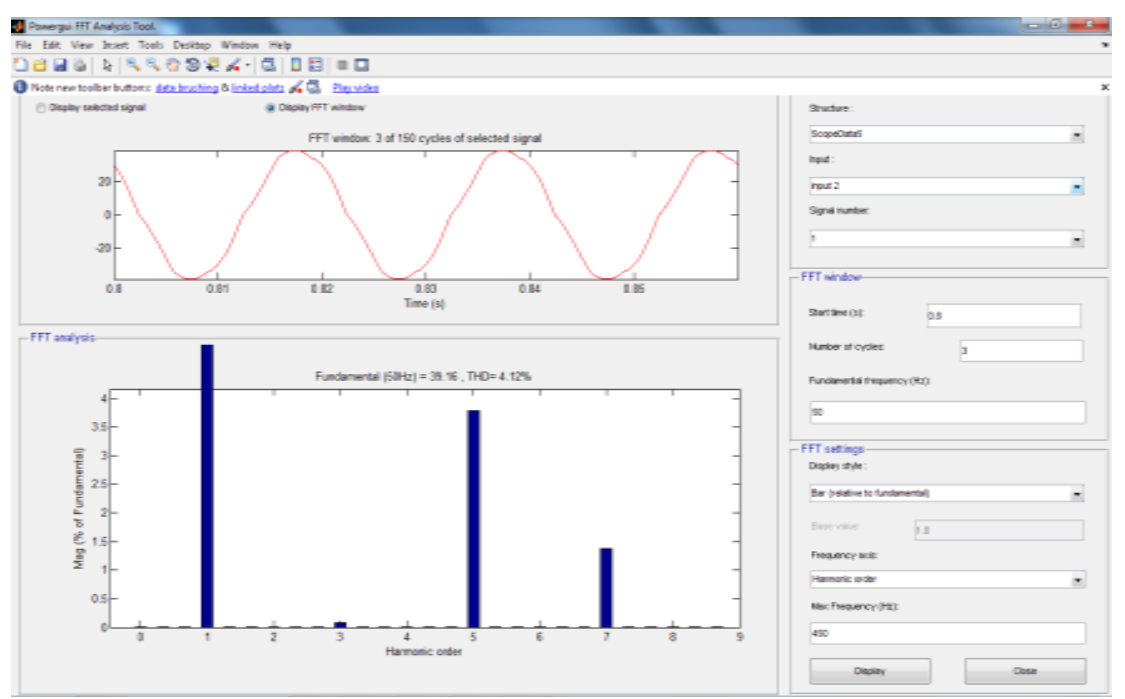

Fig.10.FFT analysis without controller(THD=4.12\%) 

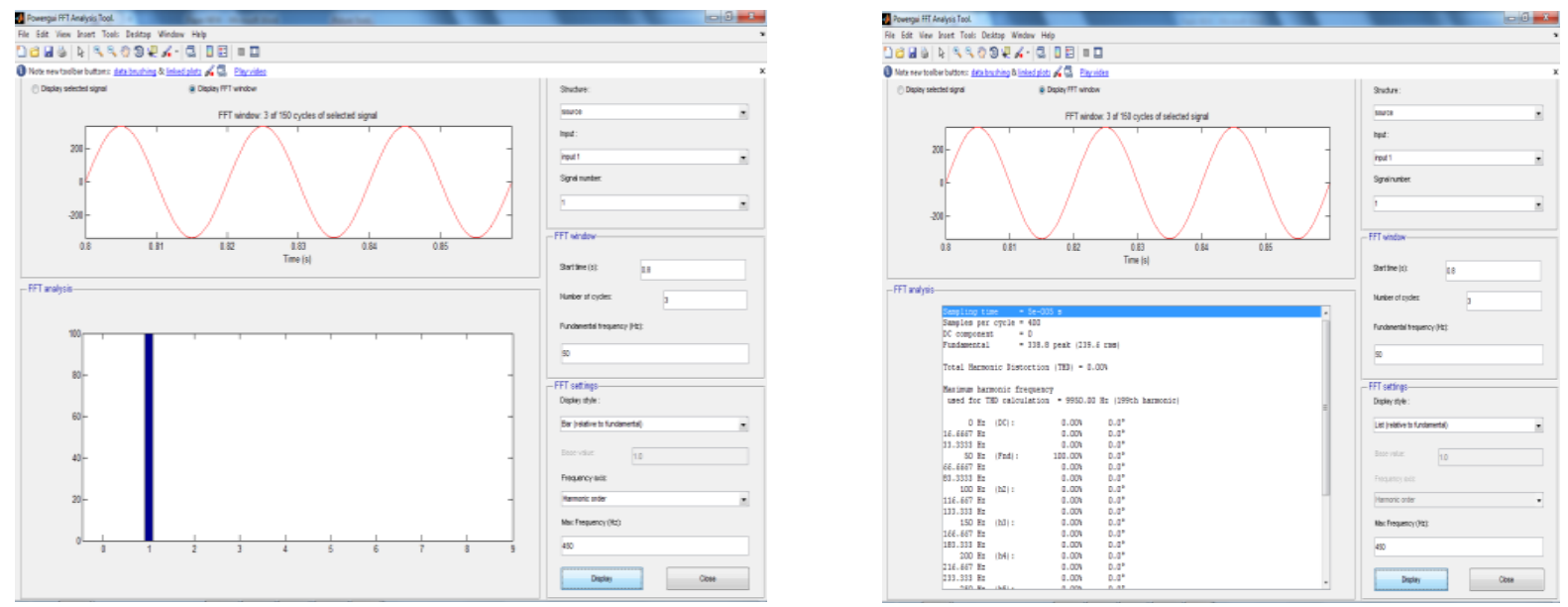

Fig.11(a)\&11(b) FFT analysis with controller(THD=0.00\%)

The Fourier analysis of the waveform is expressed and the THD of this source current at PCC without STATCOM is $4.12 \%$, as shown in Fig.10.The power quality improvement is [15] observed at point of common coupling, when the controller is in ON condition. The STATCOM is placed in the operation at $0.7 \mathrm{~s}$ and source current waveform is shown in Fig.11.with its FFT. It is shown that the THD has been improved considerably and within the norms of the standard.

\section{Conclusion}

The paper analyses the factors which are responsible for the power quality problems [16] in the wind energy conversion system and implementation of proper control scheme for power quality improvement in the wind energy conversion system connected to the grid. The proposed control scheme for the grid connected Wind energy generation system for power quality improvement is simulated using MATLAB/SIMULINK. The control scheme has a capability to cancel out the harmonic parts of the load current. It maintains the source voltage and current in-phase and support the reactive power demand for the wind generator and load at PCC in the grid system, thus it gives an opportunity to enhance the utilization factor of transmission line.

\section{References}

[1]. S.W Mohod, M.V Aware, "A STATCOM control scheme for grid connected wind energy system for power quality improvement," IEEE System Journal, Vol.2, issue 3, pp.346-352, Sept.2010

[2]. E. Muljadi and C.P. Butterfield "Power quality aspects in a wind power plant," in IEEE Power engineering June 18-20, 2006.

[3]. Sun, Tao, Chen, Z., Blaabjerg, F,: "Flicker Study on Variable Speed Wind Turbines with Doubly Fed Induction Generators", Accepted for IEEE Transactions on Energy Conversion.

[4]. A.P. Jayam, B.H. Chowdhury, "Improving the dynamic performance of wind farms with STATCOM", IEEE, 2009

[5]. S. W. Mohod and M. V. Aware," Power quality issues \& its mitigation technique in wind energy conversion," in Proc. of IEEE Int. Conf. Quality Power \& Harmonic, Wollongong, Australia, 2008

[6]. Larsson A. Flicker emission of wind turbines caused by switching operations IEEE Trans on Energy Conversion, 2002, 17(1): 119-123.

[7]. English version of Technical Regulations TF 3.2.6, "Wind turbines connected to grids with voltage below $100 \mathrm{kV}$ -Technical regulations for the properties and the control of wind turbines", Eltra and Ekraft systems, 2004.

[8]. N. G. Hingorani and L. Gyugyi, Understanding FACTS: Concepts and Technology of Flexible AC Transmission Systems, New York: IEEE, 2000.

[9]. A.Arulampalam, J.B.Ekanayake \& N.Jenkins, Application study of a STATCOM with energy storage, Proc. IEE Generation, Transmission \& Distribution, Vol. 150, No. 3, 2003, 373-384.

[10]. S. Heier "Grid Integration of Wind Energy Conversions," Hoboken, NJ: Wiley, 2007.

[11]. Indian Wind Grid Code Draft report on, Jul.2009, C-NET.

[12]. M.E. Baran, S. Teleke, L. Anderson, S. Bhattacharya, A. Huang, S.Atcitty, "STATCOM with Energy Storage for Smoothing Intermittent

[13]. Wind Farm Power", IEEE/PES, 2008.

[14]. B. Behzad Jazi, H. A. Abyaneh, M. Abedi " Power quality improvement using active filter capability in back to back convertor installed for variable speed DFIG wind energy system," 2001.

[15]. Z. Yang, L. Zhang "Integration of statcom and battery energy storage," IEEE Trans. on Power Systems, vol. 16, no. 2, pp. 254-260, May 2001.

[16]. A. Morales and J.C. Maun: "Power quality responsibilities by grid impedance assessment at a wind power production”, CIRED, Barcelona, Spain, 12-15 May 2003. 